\title{
Appreciation as Audience Response: \\ Exploring Entertainment Gratifications Beyond Hedonism
}

\author{
Mary Beth Oliver ${ }^{1} \&$ Anne Bartsch ${ }^{2}$ \\ ${ }^{1}$ Penn State University, University Park, PA \\ ${ }^{2}$ Martin Luther University Halle
}

Oliver, M. B., \& Bartsch, A. (2010). Appreciation as audience response: Exploring entertainment gratifications beyond hedonism. Human Communication Research, 36(1), 5381. doi:10.1111/j.1468-2958.2009.01368.x

The definitive version is available at http://onlinelibrary.wiley.com/doi/10.1111/j.1468$\underline{2958.2009 .01368 . x / f u l l}$

This article may not exactly replicate the final version published in the previously mentioned Journal. It is not the version of record and is therefore not suitable for citation.

Acknowledgements: We extend our thanks to Matt Jordan and Matt McAllister for their assistance with data collection. We also thank Ron Tamborini for his helpful discussions with us about the issues addressed in this article.

\section{Funding: -}

Corresponding author: mbo@psu.edu 


\begin{abstract}
This paper elaborates upon the notion of media enjoyment in the context of film viewing by proposing a complementary type of gratification that we conceptualize as appreciation. Three studies were conducted to tap into the multidimensionality of viewers' entertainment gratifications with a special focus on the domain of more serious, poignant, and pensive media experiences that are typically associated with genres such as drama, history, documentary, or art films. These studies provide evidence of and measurement for gratifications related to fun and suspense, but also gratifications related to moving and thought-provoking entertainment experiences, with all three gratifications leading to perceptions of entertainment having a more long-lasting or enduring effect. The results are discussed with regard to the theoretical conceptualization of entertainment gratification.
\end{abstract}


Appreciation as Audience Response:

\section{Exploring Entertainment Gratifications beyond Hedonism}

Although entertainment arguably accounts for the largest share of individuals' media diets, compared to other topics such as advertising and news, the systematic study of entertainment is a relative newcomer in the field of media research (Bryant, 2004). Within the last several decades, though, scholarship on the psychology of entertainment has exploded, perhaps as a reflection of the phenomenal growth of new types of entertainment such as video games, social networking sites, and mobile entertainment.

The advent of new technologies and the fast paced development of new entertainment genres and formats have required scholars to explore the diversity of gratifications that viewers (and users) derive from their entertainment consumption. Yet in general, theories on entertainment psychology have tended to focus on the response of enjoyment, exploring such questions as why viewers enjoy some types of entertainment genres, portrayals, or behaviors over others, and why different viewing situations and mood states lead individuals to select and enjoy different types of entertainment offerings over others.

The focus of enjoyment is understandable — after all, the word "entertainment" conjures up thoughts of amusement, thrills, relaxation, and diversion. Typical entertainment offerings associated with the notion of enjoyment include comedy, videogames, sporting contests, mystery novels, and the like. Yet this focus on amusement and pleasure - although capturing a large and perhaps most prominent proportion of the entertainment landscape-fails to cover the full spectrum of viewers' responses to entertainment.

The purpose of this research is to expand upon the notion of enjoyment in the context of cinematic entertainment. Namely, this paper presents three studies designed to develop measures 
tapping into the multidimensionality of viewers' entertainment experience. Importantly, in addition to assessing enjoyment as commonly understood in popular discourse and as frequently measured in extant research, an additional measure that we believe indicates appreciation is also developed to help account for the domain of more serious, poignant, and pensive media experiences and gratifications. Such experiences are commonly associated with genres like drama, history, documentary, or art films but may actually form a more pervasive aspect of entertainment experience that is present in other media genres as well, albeit to less dominant degree.

Moving and thought-provoking types of entertainment are far less well researched than fun and thrill experiences_- perhaps because they are seemingly at odds with hedonic (pleasureseeking) concerns. However, despite an understandable reluctance to categorize them under the notion of enjoyment, these media experiences and the genres specifically designed to evoke them share a number of characteristics that are commonly attributed to entertainment: Their content is narrative, mostly fictional or semi-fictional, they are an important part of how individuals spend their leisure time, and they account for some of the greatest successes at the box office. For instance, the two most commercially successful movies of all times (adjusted and unadjusted for ticket price inflation) are dramas: Gone with the Wind and Titanic.

Communication research should be able to explain the gratification potential of these moving and thought-provoking types of entertainment experiences and to specify the commonalities and differences between them and well-established entertainment phenomena such as fun and thrill experiences. Our work aims to provide research tools for a more systematic study of entertainment gratifications by exploring qualitatively different dimensions of movie experience and making them amenable to introspective measurement. 


\section{Entertainment Consumption in Hedonistic Terms}

Studies of viewers' enjoyment of media entertainment are voluminous and diverse, including studies that examine the uses that people may have for specific types of media content, or research exploring individual differences that predict greater or lesser enjoyment of particular genres. However, disposition theory, mood management, and sensation seeking are examples of theoretical perspectives that more broadly address viewers' selection of and responses to entertainment, as these theories pertain to a wide array of entertainment offerings.

The assumption that individuals' entertainment experiences reflect hedonistic considerations is perhaps most evident in mood management theory. (Zillmann, 1988, 2000; Zillmann, Hezel, \& Medoff, 1980). Empirical research has revealed abundant and robust support for the general propositions of this theory. For example, studies support the idea that individuals use media content to regulate sub-optimal levels of arousal (stress and boredom), that they show a preference for comedy when in negative mood states, and that they have a greater tolerance for negative or bad news content when in positive than negative moods (for reviews, see KnoblochWesterwick, 2006; Oliver, 2003).

The concept of sensation seeking (Zuckerman, 1994) is based on an arousal regulation framework as well, however, with a focus on individual differences in the enjoyment of novel and intense sensations and experiences that are associated with heightened arousal. The strength of the sensation seeking motive has been related to specific patterns of media use, in particular the preference for horror films and other forms of media violence (Johnston, 1995; Sparks, 1986; Tamborini \& Stiff, 1987; Zuckerman, 1996).

The conceptualization of "entertainment-as-pleasure" is also echoed in disposition theory (Bryant \& Miron, 2002; Raney, 2003; Zillmann \& Bryant, 1986)_focused on individuals' 
responses to entertainment (rather than on their selection specifically). This model argues that while viewing entertainment, viewers make moral judgments concerning the "goodness" or "badness" of the characters depicted. With these judgments in mind, the greatest level of gratification is predicted to occur when good outcomes occur for liked characters and when bad outcomes befall disliked characters. Research on disposition theory has revealed a substantial amount of empirical support across a variety of genres, suggesting that individuals experience the greatest level of enjoyment when the portrayed outcomes in media entertainment are perceived as "just" or "correct” (Raney \& Bryant, 2002; Weber, Tamborini, Lee, \& Stipp, 2008; Zillmann \& Cantor, 1977).

\section{Broadening the Scope of Entertainment Gratifications}

Early and ongoing work from a uses and gratifications perspective has drawn attention to the multidimensionality of gratifications associated with media use (for overviews, see Katz, Blumler, \& Gurevitch, 1973; Rubin, 2008; Ruggiero, 2000). Some of the gratifications studied from this perspective may actually boil down to hedonistic needs and concerns, such as the use of entertainment for purposes of overcoming loneliness (e.g., Perse \& Rubin, 1990), for escape from problems (e.g., Herzog, 1944), or simply for passing the time (Rubin, 1983). However, other gratifications such as watching for purposes of information, status-enhancement, or social interaction (Rubin, 1983) are not readily explained in hedonistic terms, and are therefore often considered to fall outside the realm of entertainment. We agree that subsuming these gratifications under the term of entertainment would over-generalize the concept, albeit for a different reason: Entertainment is usually conceptualized as an intrinsically rewarding experience or activity (cf., Vorderer, Steen \& Chan, 2006) that is sought by media users independently of 
extrinsic rewards such as obtaining useful information, social status, or the opportunity to spend time with others.

The focus of our research is on aspects of entertainment experience that are intrinsically rewarding for media users without necessarily being associated with enjoyment proper. Specifically, the popularity of mournful love songs, tragic drama, and somber motion pictures appears at odds with the idea that entertainment must necessarily be pleasant or fun in order to be gratifying. Perhaps even more puzzling is research suggesting that at certain times, individuals in negative or sad affective states often appear to have a preference for somber or mournful entertainment, including both movies (Strizhakova \& Krcmar, 2007) and music (Gibson, Aust, \& Zillmann, 2000). Some scholars have suggested that such preferences may reflect downward social comparison (Mares \& Cantor, 1992), or that they may reflect the seeking of information that may ultimately help the mournful viewer "work through" his or her negative state (Zillmann, 2000).

In contrast to finding the popularity of sad films particularly surprising or problematic, some earlier research from a uses-and-gratifications perspective not only identified similar media preferences, but also provided some possible interpretations for the appeal of such fare. For example, Katz, Gurevitch, and Haas (1973) found that in addition to using media for purposes of entertainment and relaxation, individuals also reported using media as a means of experiencing beauty and raising morale. In a similar vein, Tesser, Millar, and Wu's (1988) research on movie gratifications not only identified motivations akin to hedonic concerns (e.g., self-escape, entertainment), but also identified an additional motivation that they labeled "self-development." Relevant to the present research, the self-development motivation identified by these authors was associated with greater interest in viewing films to understand how others think and feel, and in 
viewing for purposes of experiencing strong emotions. Though promising, these findings did not generate systematic follow-up research, perhaps because the more contemplative gratification factors did not emerge in a systematic manner in other studies. For instance, much of the research in and measurement of media gratifications relies on the work of Conway and Rubin (1991) who established the following gratification factors in TV use: Pass-time, Entertainment, Information, Escape, Relaxation, and Status-enhancement.

Likewise, it is important to note that the view of more somber fare as puzzling or surprising as well as the failure of related gratification factors to emerge systematically in uses and gratification studies may reflect a bias toward studying U.S. populations and U.S. media products that may stress action films and farcical comedy. As Blakley (2001), Trepte (2008), and Klimmt and Vorderer (2009) have pointed out, individuals from different cultures and countries may respond in unique ways to different types of media content. Consequently, in other countries and cultures such gratifications may not be surprising or puzzling at all.

More recent theorizing in media entertainment has begun to address this issue by recognizing a broader range of cognitive and affective gratifications that viewers may experience. For example, Bartsch, Vorderer, Mangold, and Viehoff (2008) recently discussed entertainment gratifications in terms of meta-emotions-one's emotions about one's emotions. These authors, using an appraisal framework, suggested that the experience of entertainment reflects the appraisal of emotions experienced in the process of media use. From within this framework, then, media entertainment that elicits positive or negative emotions (such as joy or sadness, for example) may result in favorable appraisals of the emotional experience and hence positive affective reactions at the meta-level. 
Likewise, Oliver (2008) also recently attempted to broaden the scope of the entertainment experience by suggesting that in addition to seeking pleasure from entertainment consumption, individuals at times also use entertainment as a means of contemplating human poignancies and meaningful life questions - a gratification that she labeled "eudaimonia" (in contrast to hedonistic gratifications). Further, such contemplations, though gratifying, were not necessarily conceptualized as associated with positive affect, but instead were argued to reflect a blend of cognitions and positive/negative affective mixtures_ an affect that she labeled "tenderness."

Oliver's (2008) discussion of the notion of "eudaimonic" gratifications (associated with meaningfulness and contemplation) echoes Zillmann's earlier (1998) suggestion that the notion of "enjoyment" (as commonly understood) may not be an apt descriptor of the gratifications that viewers experience for all types of entertainment. Rather, Zillmann suggested that for some types of entertainment — and for tragic entertainment specifically — it may be more appropriate to consider alternative notions than pleasure:

It may be considered ill-advised, in fact, to focus on enjoyment as a redeeming value of tragedy. Perhaps we should return to Aristotle's (Poetica) declaration of tragedy's object, namely the evocation of pity, and grant redeeming value to tragic drama's capacity for honing our empathic sensitivities and for making us cognizant of our vulnerabilities, compassions, and needs for emotional wellness - a capacity that tragedy seems to posses to a greater degree than alternative dramatic forms (p. 12).

\section{Appreciation as Audience Response}

By recognizing that viewers may find some entertainment gratifying in ways that differ from enjoyment per se, scholarship in entertainment psychology is positioned to broaden its scope in numerous ways. Namely, acknowledging that individuals may not only enjoy but also 
appreciate some forms of entertainment allows for an examination of a greater diversity of media entertainment, and it also helps address the diversity of audience responses beyond those of amusement, mirth or thrills. What, then, might best capture the experience of appreciation in the context of media entertainment?

The notion of appreciation is readily applied to a variety of media content that appears to be differentiated from the sorts of entertaining diversions studied most frequently by scholars from a media-psychology perspective. For example, music appreciation, art appreciation, and appreciation of literature and poetry are familiar terms and experiences for most people. Similarly, appreciation of a tragic play, a bittersweet musical performance, or a mournful poem can be easily imagined.

Consequently, one way to broaden the concept of enjoyment may be in terms of the quality or perceived artistic value of the media content under consideration. For example, appreciation seems to suggest that the work is perceived to reflect talent or insight on the part of the creator-separate from how one may react to the art (cf., the notion of artifact emotions discussed by Tan, 1996). For example, a person may agree that he or she appreciated or found meaningful (but did not enjoy per se) a disturbing or upsetting film (e.g., Schindler's List).

In addition to notions of artistic quality, the distinction between meaningful appreciation and enjoyment may also be typified in the kinds of affective and cognitive responses that are elicited. Whereas enjoyment appears to be associated with decidedly positive affective reactions or reactions related to thrills and excitement, appreciation or meaningfulness appears to be associated with more serious if not pensive states. This distinction is similar to Cupchik's (1994) discussion of reactive versus reflective responses to aesthetic stimuli. The reactive process, akin to enjoyment in the present context, is characterized by immediate responses associated with 
pleasure and arousal, whereas the reflective process (more akin to appreciation) is characterized by a slower, more deliberative and interpretive process associated with affective blends. Similar points were also raised in Vorderer and Ritterfeld's (in press) recent discussion of the distinction between appreciation and enjoyment in the context of gaming. Namely, these authors argued that whereas enjoyment may be best described in terms of more immediate responses of pleasure, appreciation may result from the fulfillment of the higher-order goals of autonomy, competence, and relatedness (see Ryan \& Deci, 2000).

Because existing research in entertainment psychology has tended to focus on what may be considered primary emotions (joy, sadness, fear), enjoyment (or the lack thereof) is readily identified as a response to many media offerings (comedies, suspense, etc.). However, some forms of entertainment or media depictions arguably evoke complex blends of emotions and cognitive responses that appear to be associated more closely with appreciation than with enjoyment proper. For example, Edell and Burke's (1987) factor analysis of feelings that participants reported while viewing a series of advertisements revealed a "warmth" factor that included such items as touched, moved, pensive, contemplative, and emotional (see also Burke \& Edell, 1989; Escalas \& Stern, 2003; Muehling \& Sprott, 2004). Similar affective blends were reported by Larsen, McGraw, and Cacioppo (2001) who examined the relationship between happiness and sadness among individuals in three situations: moving out of dormitories at the end of the school year, graduation from college, and viewing the film Life is Beautiful. These authors found that although many people reported feeling either happy or sad, the co-occurrence of these emotional responses was not atypical. Likewise, Schaefer, Nils, Sanchez, and Philippot (2005) reported that a variety of film stimuli (e.g., Ghost, Forrest Gump, and Dead Poets 
Society) resulted in what they labeled "tender" emotions representing a blend of social emotions and affective reactions (e.g., moved, loving, affectionate, sad).

Insofar as appreciation or meaningfulness is anticipated to be associated with perceptions of greater artistic value, and with more moving and contemplative responses while viewing, it follows that appreciation may also lead to the perception of the stimuli as having a stronger and, therefore, more lasting impression. Namely, whereas enjoyment (devoid of appreciation or meaning) may be associated with fleeting feelings of pleasure and excitement, deep appreciation of some entertainment offering should result in greater levels of reflection, deeper levels of processing, and more extensive contemplation - all of which should result in more lasting or enduring responses. At the same time, however, it may be reasonable to suggest that other types of entertainment that elicit strong emotional responses (e.g., joy, fear) may also be remembered well. Consequently, this research explored whether or not lasting impressions formed a distinct type of audience response, and if so, how different facets of enjoyment and appreciation predict lasting impression.

\section{Present Research}

To summarize, extant research in entertainment psychology has tended to focus its attention on audience enjoyment over other types of emotional and cognitive gratifications that likely play important roles in the entertainment experience. A broader conceptualization that includes the additional notion of appreciation (in addition to enjoyment) should not only more fully capture the diversity of pleasures that individuals experience, but should also help account for the popularity of entertainment such as tragedies or somber dramas that current theorizing finds puzzling. As a result, the purpose of this research is to develop and validate measurements 
of audience response that represent not only enjoyment (e.g., fun, thrills) but also additional dimensions such as artistic appreciation, meaningfulness, and ultimately, lasting impression.

\section{Pilot Study}

In order to extend theoretically based ideas and to sample everyday language expressive of movie evaluation, we conducted a questionnaire study that employed open-ended items pertaining to audience responses. One hundred and forty-one participants ( 83 female, 49 male) provided descriptions of viewing experiences of liked and disliked movies by completing the following sentences: "I really like/dislike a movie when the movie is __..", "I really like/dislike a movie when the movie makes me ___." All of the expected facets of movie enjoyment and appreciation were represented in the open-ended answers. Based on these open-ended responses, an item-pool of 80 items was constructed. Each of the following facets were represented in the item pool by eight positively worded and eight negatively worded items: 1) enjoyment of fun, 2) enjoyment of suspense, 3) appreciation of artistic value, 4) appreciation of profound meaning, and 5) lasting impressions.

\section{Study 1}

To explore the dimensionality of audience responses and to select items for scale construction, we conducted an online questionnaire study. In this study we used an exploratory design, asking participants to rate the most recent full-length film they had seen so as to sample movie experiences that were more or less representative of participants' everyday media diet. We also included some additional measures to perform preliminary validation analyses. General items referring to enjoyment, appreciation, and positive/negative movie evaluation were included to verify whether the expected dimensions of audience response were in fact related to these general statements. Further, we asked participants to indicate the genre(s) of the movie because 
we expected that different film genres would be associated with different rating patterns. Given that both enjoyment and appreciation are conceptually related to the experience of emotions, we also assessed two basic dimensions of emotional experience: arousal and valence.

\section{Method}

Participants and procedure. Two hundred and sixty-eight undergraduates (155 male, 113 female) from a communication class participated in an online questionnaire study. After reading an informed consent page, participants were randomly assigned to one of eight different versions of the questionnaire that presented the scales and scale items in different orders to control for effects of order and fatigue.

Measures. The questionnaire asked participants to think of the most recent full-length film they had seen, to name the movie, to indicate the genre of the movie, and then to rate their impressions of the movie. To indicate the film genre, participants were asked select one or more of the following categories: comedy, drama, action adventure, fantasy, crime, thriller, romance, biography, history, horror, animation, documentary, sad film/tear-jerker, and science fiction, or to name other genres using an open ended answer field. The main part of the questionnaire included 80 items on different aspects of audience response (fun, suspense, meaningfulness, artistic value, and lasting impression). In addition, we included two single items "I enjoyed this movie" and "I appreciated this movie," and another four items expressive of movie evaluations in the most general sense: "This movie was really good," "This movie was really bad," "I liked this movie," and "I didn't like this movie." All evaluation items were recorded on 7-point scales ranging from 1 (strongly disagree) to 7 (strongly agree). Finally, participants were asked to rate the emotions they had experienced while watching the movie using the valence and arousal items from the SAM scale (Lang, 1980). 


\section{Results}

Exploratory factor analysis. To begin to examine the underlying dimensions of audience responses, we performed exploratory factor analyses on the initial item pool of 80 items using principle component analysis with varimax rotation. This analysis revealed 14 components with eigenvalues greater than 1 that accounted for $71 \%$ of the variance. However, an inspection of the scree plot showed that the last substantial drop in eigenvalues appeared after the fifth factor. A follow-up analysis that extracted five factors accounted for $56 \%$ of the variance. Four of the five expected facets of movie enjoyment and appreciation emerged clearly in this analysis: 1) fun, 2) suspense, 3) moving/thought provoking experience, and 4) lasting impression. However, items related to artistic value failed to form a separate factor. Primary loadings of these items were distributed across different factors. A number of artistic value items (in particular, those using the words "art," "artistic," and "aesthetic") loaded on the moving/thought-provoking dimension, whereas loadings of the remaining items (using words such as "creative," "imaginative," "a classic," or "well done") were distributed across other factors. Instead of an artistic-value factor, generally unfavorable movie evaluations emerged as the fifth factor, including items that imply a lack of fun or suspense (e.g., "This movie seemed to drag on forever," "Movies like this are no fun at all”) as well as items implying a lack of meaningfulness, artistic value, and lasting impression (e.g., "The movie was too shallow," "This movie struck me as a low-budget film"). The fact that these items did not load as negative items on the identified dimensions of audience response suggests that participants may have found it easier to specify why they liked a movie (i.e., to distinguish between different kinds of gratifications obtained) than to specify what was disappointing about a movie. Disappointing movie experiences seem to be characterized by an 
absence of any kind of gratification, whereas rewarding movie experiences include a varied spectrum of qualitatively different experiences.

To explore the possibility that artistic value might form a sixth factor besides the other four factors and generally negative evaluations, we tested a 6-factor solution (PCA with varimax rotation). However, artistic value did not emerge as an independent factor in this analysis either, rather cognitive and emotional aspects of suspense tended to form separate factors. Thus, we concluded that only four of the five aspects of audience responses considered in our study yielded independent dimensions in the data.

To further explore the reasons why artistic value failed to form an independent factor, we performed exploratory scale statistics on the 16 art-related items. Reliability estimates using Cronbachs' indicated that these items formed an internally consistent scale $(\alpha=.92)$. This seems to suggest that although the items provided a reliable measure of artistic-value judgments, these judgments did not produce unique variance in the data but seemed to be informed to a large extent by more basic evaluations reflected by the other four dimensions. Consequently, artistic value was not considered further as an independent dimension of movie experience, and was not included in subsequent analyses of the scale items. However, we decided to construct an art scale that might be useful if artistic quality is a focus for future research.

Scale construction. For each of the four dimensions as well as the additional art scale, three positively worded items were selected for scale construction. We did not include negatively worded items because it was evident from the 5-factor solution that these items did not discriminate well enough between the different dimensions but tended to form a general negative evaluation factor. Selection criteria for the scale items were high and unambiguous factor loadings in the 5-factor solution, good scale statistics in terms of reliability and inter-item 
correlation, and low redundancy in the wording of the items. The 12 items selected to represent the four dimensions fun, suspense, moving/thought-provoking experience, and lasting impression, as well as the items selected for the artistic value scale, are displayed in Table $1{ }^{1}$

To test the selected scale items' ability to distinguish between the dimensions and to explore interrelations among the factors, we conducted a factor analysis of the reduced set of 12 enjoyment/appreciation items using principal axis (PA) factoring with Promax rotation $(\kappa=4)$ and requesting four factors. Although this analysis revealed only three eigenvalues greater than 1, an examination of the scree plot suggested the extraction of an additional, fourth factor. Table 1 shows the pattern-matrix loadings of the scale items in the final 4-factor solution. Table 1 also reports the reliability estimates using Cronbach's alpha for each of the enjoyment/appreciation scales as well as for the lasting impression and artistic-value scales. All reliabilities were acceptable. Given that the test of Cronbach's alpha is sensitive to the number of items in the instrument (i.e., short scales tend to have lower alphas), these results are promising in that they indicate that the dimensions of audience response can be measured reliably using very short scales composed of three items each.

\section{Preliminary Validation Analyses}

To provide an initial assessment of validity, we first analyzed how dimensions of fun, suspense, and moving/thought-provoking experience predicted general movie evaluation to verify that the three dimensions were, in fact, related to these general evaluations. We also examined how these three audience responses predicted the two basic dimensions of emotional experience, arousal and valence, that were assessed using the SAM (Lang, 1980). Finally, we examined how the three dimensions predicted perceptions of lasting impression. 
First, a general favorability rating was computed by averaging together four items measuring general evaluations (i.e., "really good," "really bad," "liked movie," "didn't like movie"). Higher scores on this scale evidenced more favorable impressions of the movie, Cronbachs' $\alpha=.92, M=6.12, S D=1.15$. In terms of enjoyment and appreciation ratings, we noted that ratings of "I enjoyed this movie" and "I appreciated this movie" were strongly correlated at $r=.51, p<.001$ indicating that participants did not make a strong distinction between these two statements - an issue that we tried to rectify in Study 2. However, given the strong correlation in this instance, we opted to examine the relative ratings of appreciation vs. enjoyment so as to more clearly differentiate the two impressions. Consequently, we created a new variable by subtracting enjoyment ratings from appreciation ratings, with higher values indicating higher levels of appreciation relative to enjoyment, and lower ratings indicating higher levels of enjoyment relative to appreciation.

Table 2 shows the results of these regression analyses. In terms of general favorability ratings, only the dimensions of fun and moving/thought-provoking were significant positive predictors. Consistent with predictions concerning distinctions between enjoyment and appreciation, the fun dimension was associated with greater emphasis on enjoyment over appreciation, whereas the moving/thought-provoking dimension was associated with greater emphasis on appreciation over enjoyment. In terms of arousal, the strongest predictor was suspense (as one would expect), though fun was also a significant predictor, albeit to a lesser degree. For emotional valence, we expected a more varied pattern of associations because it seems that both positive and negative emotions can contribute to media enjoyment and appreciation (cf. Sparks, 1991; Oliver, 1993). Specifically, we assumed that the fun factor should reflect positive emotionality, whereas suspense and moving/thought-provoking experiences 
should be related to the experience of more negatively valenced emotions (e.g., fear and sadness respectively). These expectations were confirmed. Finally, these analyses also showed that all three dimensions of audience response were positive predictors of lasting impression, though the strongest predictor was for the moving/thought-provoking dimension.

Although these analyses are generally consistent with expectations, these findings need to be interpreted with caution due to an unbalanced distribution of film genres in the data set. Of the 268 participants, 150 reported that the most recent movie they had seen (i.e., the movie they had rated) was a comedy. Thus, the magnitude of the predictors possibly overestimates the relative influence of fun on general movie evaluation compared to other gratifications that are less typical of comedies.

To further examine the validity of these scales in relation to film genre, we divided the sample into groups that had rated similar genre types. Note that participants were allowed to select multiple genres for the films that they had most recently seen (e.g., a film may have been characterized as both a comedy and a romance). Because film genres were not mutually exclusive and because some genres were named very infrequently, we first created a simplified genre variable reflecting only the most frequent genre categories named by participants (more than 50 times): comedy, drama, and action-adventure/thriller (action-adventure and thriller were combined into one category because participants frequently indicated both genres as representing the film chosen). The simplified genre variable was coded only if participants' genre ratings identified their film as representing only one of the three genre types. Of the 268 participants, 211 met the criteria for coding this simplified genre variable, with 119 "pure" cases of comedies, 41 dramas, and 51 action/thrillers. 
Based on the simplified genre variable, we conducted a repeated measures analysis of variance to examine ratings on the three dimensions of appreciation/enjoyment among participants who had rated a comedy, a drama, or an action/thriller. This analysis revealed the expected Genre X Rating interaction, Wilks' $\Lambda=0.43, F(4,414)=53.67, \eta_{\mathrm{p}}{ }^{2}=.34, p<.001$. As Table 3 shows, comedies were most strongly associated with fun, action/thrillers with suspense, and dramas with moving/thought provoking experiences. This analysis was limited, however, in that the grouping variable was coded post hoc. Therefore we aimed to replicate this finding experimentally in Study 2 using random assignment of participants to rate movies of different genres.

\section{Discussion}

Study 1 provided first evidence that in addition to well-researched entertainment gratifications such as mood management and sensation seeking, audiences are attracted by a more varied spectrum of gratifying movie experiences that seem to include appreciation of moving and thought provoking experiences. Exploratory factor analysis of the initial item pool yielded four dimensions, two of which seemed to reflect experiences that have been commonly associated with the notion of media enjoyment (fun and suspense), whereas a third factor corresponded to the notion of media appreciation outlined above (moving/thought provoking). The fourth factor (lasting impression) appeared to be an outcome of heightened audience response on the other three dimensions as it was significantly predicted by each of them.

Both fun and moving experiential dimensions were related to favorable movie evaluation, suggesting that despite the qualitative differences among them, both dimensions cover a specific kind of rewarding experience that contributes to entertainment gratification. Likewise, enjoyment and being moved were related to enjoyment versus appreciation ratings in the expected direction. 
Surprisingly, suspense did not predict favorable movie evaluation and enjoyment vs. appreciation ratings. All three dimensions predicted heightened perceptions of lasting impression, suggesting that entertainment eliciting strong audience response has a more lasting effect on viewers. Preliminary validation analyses of the three-item scales we constructed for measuring these dimensions revealed an encouraging degree of consistency with expected rating patterns for different film genres and the assumed relations of the scales with emotional arousal and valence.

\section{Study 2}

The purpose of Study 2 was to confirm the factor structure of the movie enjoyment and appreciation scales obtained in Study 1 and to complement the preliminary validation analyses. Moreover, we hoped to address some methodological limitations associated with the explorative design of Study 1, in particular the unbalanced distribution of genres, the post hoc creation of the genre variable, and the less-than-optimal level of discrimination between the two single items "I enjoyed this movie" and "I appreciated this movie." To address these limitations, participants in Study 2 were randomly assigned to rate movies from three different film lists, each of which represented a specific genre category. Regarding movie enjoyment and appreciation, we used anchored rating scales instead of the two single items intermixed in the large item pool in study 1 , and we included a specific instruction that prompted participants to consider them as independent dimensions of movie experience before making their ratings.

\section{Pretest and Preparation of the Film Lists}

A pretest was conducted to prepare the film lists for Study 2. Seventy-five undergraduates rated a list of 32 movies using an online questionnaire. The movies in the list were supposed to reflect three broad categories of film genres identified by Hall (2005, p. 385): 1) serious films 
(drama, classics, documentary), 2) light films (comedy, romance), and 3) action-oriented films (action, thriller, horror, science fiction). Participants indicated whether they had seen the movie and coded their reaction to each they had seen using one of four categories: "enjoyment only," "appreciation only," "both enjoyment and appreciation," "neither enjoyment nor appreciation." Generally, serious films received the most frequent appreciation ratings (appreciation only, or both). Light films predominantly received enjoyment-only ratings. Action-oriented films typically received mixed ratings including enjoyment only, both, or neither.

We prepared three film lists composed of movies that were well known among the pretest sample and reflected typical rating patterns. Film list 1 (serious films) included the movies with the most frequent appreciation ratings: Schindler's List, A Beautiful Mind, To Kill a Mockingbird, Crash, and Hotel Rwanda. Film list 2 (light movies) was composed of the movies with the most frequent ratings of enjoyment only: American Pie, There's Something About Mary, Meet the Parents, Wedding Crashers, and 40-Year-Old Virgin. Film list 3 included movies with mixed ratings that were typical of action-oriented genres: Casino Royale, Transformers, Con Air, Saw, and Scream. We also included a control condition that asked participants to rate the most recent movie they had seen, as in Study 1. This condition was included to compare the three film list conditions with movie experiences that were more representative of participants' everyday media diet.

Based on the pretest we expected that among the three film lists, serious films (list 1) would receive the highest level of appreciation ratings as well as the highest scores on moving/thought-provoking experiences. Further, we assumed that light films (list 2) would receive the highest scores on enjoyment and on the fun scale. Due to the mixed ratings in the 
pretest, we made no predictions concerning enjoyment and appreciation ratings of actionoriented films; however, we expected that these films would receive the highest suspense ratings.

In addition to the differential rating patterns for the three film list conditions, we expected differences in the scales' ability to predict movie enjoyment and appreciation. We expected that moving/thought-provoking experiences should predict movie appreciation, whereas fun and suspense should predict enjoyment. We further hoped to replicate the associations of the scales with emotional valence and arousal observed in Study 1. Finally, we expected that, like in Study 1, all three dimensions should predict higher ratings of lasting impression, though we anticipated that the strongest predictor would be moving/thought-provoking experiences.

\section{Method}

Participants and procedure. Two hundred and eighty-five undergraduates (142 male, 142 female) participated in the study that involved completion of an online questionnaire. After reading an informed consent page they were randomly assigned to one of four different versions of the questionnaire that presented one of the three film lists or the instruction to name and rate the most recent movie they had seen. With each condition, two versions of the questionnaire were employed that varied the presentation order of the scale items to account for potential problems with question order or fatigue.

Measures. Participants were either asked to select a film among one of the three film lists that they liked best, or to think of the most recent movie they had seen. To avoid potential problems with demand characteristics, in the film-list conditions, the genre of the five target movies was disguised by including an equal number of fake titles suggestive of other genres (e.g., the serious list was complemented with fake comedy and action titles). After selecting a film, participants were then asked to indicate the genre of the movie they had chosen. In this 
study, we used a reduced set of genre labels that has been identified by Hall (2005, p.385) as typical exemplars of three broad categories: serious films (classics, drama, documentary), light films (comedy, romance), and action-oriented films (action, horror, science fiction, thriller). As in Study 1, participants were allowed to select multiple genre labels. Next, participants were asked to rate the emotions they had experienced while watching the movie using the valence and arousal scales of the SAM (Lang, 1980). The main part of the questionnaire included the 12 items selected for scale construction in Study 1. All evaluation items were accompanied by a 7point scale ranging from 1 (strongly disagree) to 7 (strongly agree).

Finally, we noted that ratings of the items "appreciation" and "enjoyment" in Study 1 were strongly correlated, suggesting that participants' casual use of these terms are generally similar. Consequently, to better distinguish between these two responses, in this study movie enjoyment and appreciation were assessed using 7-point Likert scales with the anchor labels: "no enjoyment at all—strong enjoyment," and "no appreciation at all—strong appreciation." The scales were accompanied by the following instructions: "To enjoy a movie and to appreciate it can sometimes be different kinds of things. Sometimes we enjoy a movie although we don't appreciate it, or we appreciate a movie although we don't enjoy it. How would you classify your movie experience to the movie that you chose in terms of enjoyment and appreciation?" In order to avoid an influence of this somewhat suggestive instruction on other responses, we positioned the two rating scales at the end of the questionnaire.

Results

A confirmatory factor analysis was conducted to assess the factor structure of the four dimensions of audience response revealed in Study 1. In this analysis, all factor loadings were freely estimated by constraining the variance of the factors to 1 . This analysis revealed an 
acceptable fit, $\chi^{2} / \mathrm{df}=2.28, \mathrm{CFI}=.97, \mathrm{RMSEA}=.07$, with all factor loadings greater than .68 . Because gender differences in movie preferences have been reported in the research literature, we also examined whether or not the factor loadings varied for male and female participants. The results of this analysis showed that the factor structure did not differ between genders, $\chi^{2}(12)=$ 16.96, $p=.15$. As in Study 1, reliability estimates of the scales computed by averaging the items associated with each dimension revealed good internal consistency; fun: $\alpha=.89$, suspense: $\alpha=$ .88 , moving/thought-provoking experience: $\alpha=.89$, lasting impression: $\alpha=.84$.

Next, we analyzed participants' genre ratings in the film list conditions to verify that the movies were perceived to fit the target genre categories. Of the 55 participants who rated a movie from the first list (serious films), 54 selected one or more serious genres (drama, classic, documentary); all of the 80 participants who rated a movie from the second list selected light genres (comedy, romance), and all 62 participants who rated a movie from third list selected action-oriented genres (action, thriller, horror, science-fiction). Secondary ratings in other genre categories were generally below $20 \%$. Thus, the movies in our film lists seemed to be perceived by participants as prototypical exemplars of the target genres. In the control condition there was a relatively balanced distribution of genres. Of the 69 participants in this condition, 26 reported serious genres, 31 light genres, and 37 action-oriented genres.

Next, we analyzed participants' enjoyment and appreciation ratings. A correlation of $r=$ $.23, p<.001$ between enjoyment and appreciation indicated a sufficient degree of discrimination to consider them as distinct variables. Thus, our efforts to tease enjoyment and appreciation ratings apart seemed to be effective. Subsequently, a repeated measures analysis of variance was conducted to examine differences in enjoyment versus appreciation scores as a function of film condition. This analysis revealed the expected Ratings X Film Condition interaction, Wilks' $\Lambda=$ 
$0.69, F(3,260)=35.29, \eta_{\mathrm{p}} 2=.29, p<.001$. Table 4 reports the means and standard errors associated with the interaction and shows that serious movies (list 1) received significantly higher appreciation ratings than light films (list 2), action-oriented films (list 3), and films that participants had recently seen (the control condition). In contrast, enjoyment ratings were highest for the light films, and significantly more so than for serious and action-oriented movies.

To examine the validity of our scales measuring dimensions of audience response, a repeated measures ANOVA was employed to examine differences in ratings on the three scales as a function of film condition. This analysis revealed the expected Ratings X Film Condition interaction, Wilks' $\Lambda=0.36, F(6,518)=57.45, \eta_{\mathrm{p}}{ }^{2}=.40, p<.001$ (see Table 5). As expected, ratings of fun were highest for the light films, ratings of suspense were highest for the actionoriented films, and ratings of moving/thought-provoking were highest for the serious films.

The final set of analyses consisted of a series of regression analyses to examine how dimensions of audience response predicted five different variables: the single-item measures of enjoyment and appreciation, the arousal and valence scales of the SAM (Lang, 1980), and perceptions of lasting impression. To explore the relationship between our scales and the outcome variables beyond the association created by genre differences, these analyses controlled for film condition by entering dummy codes in the first step of a hierarchical regression, and entering our scales on the second step of the equation (see Table 6). As expected, the appreciation item was predicted by higher ratings of moving/thought-provoking, and the enjoyment item was predicted by higher levels of fun. Surprisingly, suspense was not a significant predictor of enjoyment. However, the analysis of arousal showed that suspense was a significant predictor, unlike any of the other rating variables in the equation. The analysis of positive valence showed that higher ratings of fun and (to a lesser extent) lower ratings of 
suspense were significant predictors. Finally, as in Study 1, all three dimensions of audience response predicted higher levels of lasting impression, though the strongest predictor was moving/thought-provoking experiences.

\section{Discussion}

The results of Study 2 confirm the factor structure of the newly developed audience response scales and complement the preliminary validation analyses in Study 1 . The 4-factor structure proved to be stable in the confirmatory factor analysis and did not differ for males and females. The Rating X Genre interaction revealed in Study 1 was substantiated using random assignment of participants to rate movies of different genres. Furthermore, the methodological approach employed to tease enjoyment and appreciation ratings apart was effective in allowing us to perform regression analyses of the scales' predictive validity concerning these items separately. As expected, moving/thought-provoking experiences emerged as a significant predictor of movie appreciation, whereas the fun scale predicted enjoyment. However, suspense did not predict movie enjoyment. In terms of emotional arousal and valence, suspense predicted arousal and negative valence, whereas fun predicted positive valence. Finally, although the three dimensions of audience response indicated different patterns indicative of enjoyment and appreciation, all three scales contributed to heightened perceptions of lasting impression.

\section{Study 3}

To add to the ecological validity of the results obtained in Studies 1 and 2 we conducted a third study using full-length films as stimuli. This time, all participants rated the same movies, allowing us to explore whether the factor structure and predictive validity of the scales still hold when variance in the rating scores is confined to individual differences in perception and experience of the same stimulus movie. 


\section{Method}

Participants and procedure. Three hundred and sixteen undergraduates from a film class participated in the study. Participants had been assigned to watch the stimulus movies as part of class work independently of the present study. The movies were presented to the film class at a regular movie theater at intervals of one and two weeks respectively. Sample sizes were slightly different for the three movies due to varying attendance: 214 rated The Graduate (USA, 1967), 223 rated Bladerunner (USA, 1982), and 276 rated Dr. Strangelove or: How I Learned to Stop Worrying and Love the Bomb (UK, 1964). Immediately after the screening, participants rated the movies using Interwrite ${ }^{\mathrm{TM}}$ PRF Clickers. These clicker devices consist of hand-held response systems (the size of a remote control) that interface via a radio frequency with PowerPoint ${ }^{\mathrm{TM}}$ software. In this study, the items and the accompanying 7-point rating scales were displayed on the screen one item at a time. Participants responded to the items by clicking the corresponding number code on their devices. The response data were transmitted from the devices to a server and stored in csv format.

Measures. Because the rating task was completed during class time, the questionnaire for Study 3 had to be as short as possible. Therefore, in addition to the 12 scale items, we included only 3 items reflecting general movie evaluation "This was a good movie," "Overall, I enjoyed this movie," and "Overall, I appreciated this movie." As in Study 1, we expected that participants would not make a strong distinction between them. Consistent with this expectation, for each of the movies, these items were strongly correlated (all $r \mathrm{~s}>.65$ ). However, to compare our analyses with that done in Study 1, one of the items was employed to reflect general favorable evaluations: "good movie"—as the word "good" seems to reflect positive evaluations in the most general sense absent the more specific connotations associated with "enjoyed" or "appreciated." 
On the other hand, to distinguish between the relative weight given to appreciation versus enjoyment, the difference of these two ratings was computed, with higher scores reflecting relatively greater weight given to appreciation, and lower scores reflecting relatively greater weight given to enjoyment.

Results

First, we conducted confirmatory factor analyses on the 12 scale items for each of the three movies. Table 7 reports the fit statistics associated with these three analyses, as well as the reliabilities, means, and standard deviations of all of the scales created. These analyses suggest generally acceptable levels of fit for the scales and good levels of reliability.

To analyze the predictive validity of the scales, regression analyses were conducted, using the dimensions of audience response to predict the general evaluation of the movies, the relative weight given to appreciation versus enjoyment, and perceptions of lasting impression (see Table 8). As in Study 1, only ratings of fun and moving/thought-provoking experiences were significant predictors of general favorable evaluations. Likewise, ratings of fun were generally associated with greater weight given to enjoyment than to appreciation ratings, whereas ratings of moving/thought-provoking experiences were generally associated with greater weight given to appreciation. However, these patterns were rather weak and were evident for only two of the three films. It is important to keep in mind, however, that scores on the singleitem appreciation and enjoyment items were strongly correlated given that we made no attempt to tease them apart as in Study 2. Consequently, the general direction of the associations are supportive of the notion that appreciation is more strongly indicative of moving/thoughtprovoking, and enjoyment of fun. Finally, higher ratings of fun, moving/thought-provoking, and (to a lesser extent) suspense were associated with greater ratings on the lasting-impression scale. 
These findings are generally consistent with findings from Studies 1 and 2, though here, fun served as a stronger predictor, and suspense was a weaker predictor. Given the absence of stimulus-related variance in these analyses, it is encouraging that similar (albeit less clear cut) patterns of results emerged as in studies 1 and 2 . This seems to indicate that the newly developed measures of fun, suspense, and moving/thought-provoking experiences were not capturing only differences in the gratification potential of different film genres but were also sensitive to more subtle differences in gratifications obtained by different individuals from watching the same stimulus movie.

\section{Follow-up Analyses}

Finally, we were interested to follow up an unexpected result that emerged throughout the three studies, namely the failure of suspense to predict enjoyment and favorable movie evaluation in the regression analyses. This seems to be at odds with existing research on sensation seeking (e.g., Zuckermann, 1994; 1996) and on the enjoyment of horror (e.g., Sparks, 1991) which found that experiences of thrill and arousal contribute to media enjoyment, at least in certain individuals. Thus, we were interested to explore whether the expected effects of suspense could be observed on the level of zero-order correlations. In Study 1, suspense was significantly related to favorable movie evaluation $(r=.23, p<.001)$ but was unrelated to relative ratings of enjoyment vs. appreciation $(r=.07, p>.10)$. In study 3 a similar pattern of results emerged for all three movies. Suspense showed moderate to high correlations with favorable movie evaluation (The Graduate: $r=.36, p<.001 ;$ Bladerunner: $r=.71, p<.001 ;$ Dr. Strangelove: $r=.49, p<.001$ ), but was unrelated to relative ratings of enjoyment vs. appreciation (The Graduate: $r=.06, p>.10 ;$ Bladerunner: $r=-.01, p>.10 ;$ Dr. Strangelove: $r=$ $.09, p>.10)$. Finally, in Study 2 suspense was unrelated to ratings of enjoyment $(r=.01, p>$ 
.10), however, there was an unexpected correlation with appreciation $(r=.35, p<.001)$. Thus, our follow-up analyses suggest that, as established in previous research, suspense does contribute to favorable media evaluation on the level of zero-order correlations. At the same time, however, these analyses raise additional doubts about the classification of suspense under participants' everyday concept of enjoyment as opposed to appreciation. Given that suspense was not our primary focus, we propose that future research should more closely examine whether or not the gratification potential of suspense is dependent on more basic gratification factors such as fun or moving/thought-provoking experiences as our regression results seem to suggest.

\section{General Discussion}

We conducted three studies to explore experiential dimensions of audience response, with a special focus on the largely neglected domain of more serious, poignant, and pensive media experiences and gratifications we conceptualize as appreciation. Overall, the results obtained in these studies are consistent with the assumption that moving/thought-provoking experiences form a distinct factor of gratifying movie experiences. Further, these studies provided evidence that moving/thought-provoking experiences were more closely related to single-item measures of appreciation than enjoyment, and fun was more closely related to enjoyment than appreciation. The analyses of different movie genres revealed that dramas and more serious films received the highest ratings on the moving/thought-provoking scale compared to movies pertaining to other genre categories (comedy/light films, and thriller/action oriented films). Hence, our ideas about which experiential qualities are conceptually related to movie appreciation, and which film genres typically evoke these experiences seem to be largely congruent with everyday concepts and perceptions of the study participants.

In terms of the two scales that we had initially conceptualized as indicating enjoyment, 
fun and suspense, results were more complex than expected. Specifically, these studies generally found that ratings of fun but not suspense were predictive of higher levels of enjoyment. These findings seem to suggest that the scholarly concept of media enjoyment which is commonly understood to cover both fun and thrill experiences is broader than the everyday notion of enjoyment which seems to focus primarily on fun.

The mixed pattern of results for fun and suspense, as well as the additional audience response of moving/thought-provoking experiences suggest that a reconsideration of the concept of media enjoyment might be warranted to take into account the similarities and differences between experiential qualities that contribute to entertainment gratification. It seems that at least three concepts are needed to cover the full range of experiential qualities that are entertaining in the sense that they are intrinsically rewarding for media users to experience: First, a concept is needed that corresponds to the natural language use of the term "enjoyment" that refers primarily to the experience of fun and positively valenced emotions, and is associated with "light" genres such as comedy and romance. Second, a concept is needed that deals with thrilling and suspenseful experiences that are typically associated with action-oriented genres such as action, thriller, and horror and that is characterized by emotional arousal and negative valence. A third concept that is needed is one that covers moving and thought-provoking experiences that are more akin to the everyday language use of the term "appreciation" and that is typically associated with serious genres such as drama, classics, and documentary.

Arguably, there may be good reasons to subsume one, two, or even all three of these concepts under the term of "media enjoyment" (cf., Nabi \& Krcmar, 2004; Oliver, 2007; Vorderer, Klimmt, \& Ritterfeld, 2004), and particularly since two of the three (fun and moving/thought-provoking experiences) were related to more favorable general evaluations, and 
since all three were shown to predict higher ratings on lasting impression. However, despite the liberty of science to define the scholarly use of terms like "enjoyment" or "appreciation" based on theoretical considerations, any such definition must resonate with empirical findings concerning how individuals ultimately experience their responses and the terms that they use to describe their experiences. As such, our results draw attention to qualitative differences in the types of media experiences that contribute to entertainment gratification and positive media evaluation, and point to the relevance of extending the focus from well-researched entertainment gratifications such as mood management and sensation seeking to the domain of appreciation. Based on the results of the present research we propose the following working definition of appreciation as an audience response: an experiential state that is characterized by the perception of deeper meaning, the feeling of being moved, and the motivation to elaborate on thoughts and feelings inspired by the experience.

It is important to point out that the experience of appreciation is not confined to a specific genre or type of media content. Light and action-oriented films, though lower on ratings of appreciation than dramas, were not devoid of appreciation. Similarly, though dramas were lower on enjoyment than other genres generally, they, too, were not devoid of enjoyment. Consequently, the experience of enjoyment and appreciation should not be assumed to form mutually exclusive categories of movie experiences, nor opposite ends of a continuum. Rather, they can best be characterized as a set of gratification factors that can (and regularly do) co-occur in entertainment experience. Whereas the results of Studies 1 and 2 indicate that the relative salience of these gratifications varies as a function of the gratification potential associated with different film genres, Study 3 draws attention to the variance in gratifications obtained from the same movie by different individuals. Likewise, the regression analyses in Study 2 indicate that 
these gratification factors predict variance in emotions, movie evaluation, and lasting impression over and above the variance explained by the film genre.

The pervasiveness of appreciation as an audience response raises important theoretical questions about the nature of entertainment gratification. Whereas the fun and suspense dimensions are covered by well-established gratification models such as mood management and sensation seeking, the experience of appreciation seems to require additional investigations that take into account the complex interplay of emotion and cognition in media use. As already mentioned, the notion of eudaimonic happiness, i.e., striving for greater insight, meaning, and purpose in life, might offer a new perspective on entertainment gratification (cf. Oliver \& Raney, 2008; Waterman, 1993). The intuition of ancient philosophers Plato and Aristotle that pleasureseeking is not the be-all and end-all of human striving and behavior is also reflected in more recent theorizing related to the concept of intrinsic motivation. Intrinsic motivation refers to the gratification individuals derive from experiences of challenge and mastery (cf. Csikszentmihalyi, 1990; Moneta \& Csikszentmihalyi, 1996; Ryan \& Deci, 2000; Vorderer, Steen, \& Chan, 2006). It is thought to arise when an individual's physical or mental skills are challenged but not overcharged by a task, so that the activity is associated with a sense of mastery and selfeffectiveness that is gratifying independent of other outcomes or extrinsic rewards.

A possible explanation of how emotional involvement might foster this rewarding state of intrinsic motivation can be derived from cognitive theories of emotion (e.g., Lazarus, 1991; Scherer, 2001). These theories assume that emotions serve to signal challenges and threats to an individuals' well-being that need to be dealt with by taking action both physically and mentally. To address the cognitive part of the challenge as an emotionally involved observer of media content and to deal with it in meaningful ways may result in a sense of mastery and self- 
effectiveness that is rewarding for media users. This complementary account of entertainment gratification that is based on the role of emotions as sources of cognitive challenge and mastery experiences seems to capture both cognitive and emotional aspects of appreciation that are implied in the present studies, but clearly more research is needed to substantiate this speculative account.

With these addition questions and avenues for research in mind, we are also mindful of the limitations of the current research that we hope future studies may attempt to address. First, as alluded to previously, these studies suffer from employing a narrow sample of respondentsindividuals who are college students from the U.S. (Klimmt \& Vorderer, 2009; Trepte, 2008). Perhaps as a result of the samples employed, the importance of fun, enjoyment, and pleasure was emphasized as an important audience response. Future studies that employ a more diverse sample of cultures and age ranges to allow for comparative findings would clearly add to the breadth of this research.

It is our hope that future research will also consider a broader range of measurement techniques than was employed in these studies. Here, we focused all of our attention on selfreported reactions. This tactic makes sense in the context of initially identifying the diversity of audience responses. However, additional measures such as behavioral indicators of audience response (e.g., facial expression, physiological data) or thought-listing techniques to tap into cognitive responses would certainly add to the findings obtained here.

With these limitations in mind, our research represents exploratory first steps in operationalizing the multi-dimensional nature of media entertainment gratifications. Although popular references to such gratifications routinely employ the word "enjoyed" to refer to audience response, we hope that our research makes clear that "enjoyment" may be too obtuse to 
aptly cover the range of gratifications that audiences experience. Given that entertainment can make us laugh, provide us with thrills, and move us to tears — and yet be perceived as fulfilling and gratifying - is illustrative of the need to more carefully consider the emotional and cognitive roles that entertainment plays in the lives of its viewers. 


\section{References}

Bartsch, A., Vorderer, P., Mangold, R., \& Viehoff, R. (2008). Appraisal of emotions in media use: Toward a process model of meta-emotion and emotion regulation. Media Psychology, 11, 7-27.

Blakely, J. (2001). Entertainment goes global: Mass culture in a transforming world. Los Angeles: Annenberg School for Communication, University of Southern California, The Norman Lear Center.

Bryant, J. (2004). Critical communication challenges for the new century. The Journal of Communication, 54, 389-401.

Bryant, J., \& Miron, D. (2002). Entertainment as media effect. In J. Bryant \& D. Zillmann (Eds.), Media effects: Advances in theory and research (2nd ed., pp. 549-582). Mahwah, NJ: Lawrence Erlbaum Associates.

Burke, M. C., \& Edell, J. A. (1989). The impact of feelings on ad-based affect and cognition. Journal of Marketing Research, 26, 69-83.

Conway, J. C., \& Rubin, A. M. (1991). Psychological predictors of television viewing motivation. Communication Research, 18, 443-463.

Csikszentmihalyi, M. (1990). Flow: The psychology of optimal experience. New York: Harper Collins.

Cupchik, G. C. (1994). Emotion in aesthetics: Reactive and reflective models. Poetics, 23(1-2), 177-188.

Edell, J. A., \& Burke, M. C. (1987). The power of feelings in understanding advertising effects. Journal of Consumer Research, 14, 421-433. 
Escalas, J. E., \& Stern, B. B. (2003). Sympathy and empathy: Emotional responses to advertising dramas. Journal of Consumer Research, 29, 566-578.

Gibson, R., Aust, C. F., \& Zillmann, D. (2000). Loneliness of adolescents and their choice and enjoyment of love-celebrating versus love-lamenting popular music. Empirical Studies of the Arts, 18, 43-48.

Hall, A. (2005). Audience personality and the selection of media and media genres. Media Psychology, 7, 377-398.

Herzog, H. (1944). What do we really know about daytime serial listeners? In P. F. Lazarsfeld \& F. N. Stanton (Eds.), Radio research 1942-1943 (pp. 3-33). New York: Duell, Sloan \& Pearce.

Johnston, D. D. (1995). Adolescents' motivations for viewing graphic horror. Human Communication Research, 21, 522-552.

Katz, E., Blumler, J. G., \& Gurevitch, M. (1973). Uses and gratifications research. Public Opinion Quarterly, 37, 509-523.

Katz, E., Gurevitch, M., \& Haas, H. (1973). Use of mass media for important things. American Sociological Review, 38, 164-181.

Klimmt, C., \& Vorderer, P. (2009). Media entertainment. In C. R. Berger, M. E. Roloff \& D. Roskos-Ewoldsen (Eds.), The handbook of communication science (pp. 345-361). Thousand Oaks, CA: Sage.

Knobloch-Westerwick, S. (2006). Mood management: Theory, evidence, and advancements. In J. Bryant \& P. Vorderer (Eds.), Psychology of entertainment (pp. 239-254). Mahwah, NJ: Lawrence Erlbaum Associates. 
Lang, P. J. (1980). Behavioral treatment and bio-behavioral treatment: Computer applications. In J. B. Sidowski, J. H. Johnson, \& T. A. Williams (Eds.), Technology in mental health care delivery systems. Norwood, NJ: Ablex.

Larsen, J. T., McGraw, A. P., \& Cacioppo, J. T. (2001). Can people feel happy and sad at the same time? Journal of Personality and Social Psychology, 81, 684-696.

Lazarus, R. S. (1991). Emotion and adaptation. Oxford, England: Oxford University.

Mares, M. L., \& Cantor, J. (1992). Elderly viewers' responses to televised portrayals of old age: Empathy and mood management versus social comparison. Communication Research, $19,459-478$.

Moneta, G. B., \& Csikszentmihalyi, M. (1996). The effect of perceived challenges and skills on the quality of subjective experience. Journal of Personality, 64, 275-310.

Muehling, D. D., \& Sprott, D. E. (2004). The power of reflection: An empirical examination of nostalgia advertising effects. Journal of Advertising, 33(3), 25-35.

Nabi, R. L., \& Krcmar, M. (2004). Conceptualizing media enjoyment as attitude: Implications for mass media effects research. Communication Theory, 14, 288-310.

Oliver, M. B. (1993). Exploring the paradox of the enjoyment of sad films. Human Communication Research, 19, 315-342.

Oliver, M. B. (2003). Mood management and selective exposure. In J. Bryant, D. RoskosEwoldsen, \& J. Cantor (Eds.), Communication and emotion: Essays in honor of Dolf Zillmann (pp. 85-106). Mahwah, NJ: Lawrence Erlbaum Associates.

Oliver, M. B. (2007). Appreciation vs. enjoyment: Exploring the diversity of audience response to entertainment. Paper presented at the annual conference of the International Communication Association. 
Oliver, M. B. (2008). Tender affective states as predictors of entertainment preference. Journal of Communication, 58, 40-61.

Oliver, M. B., \& Raney, A. A. (2008, May). Development of hedonic and eudaimonic measures of entertainment motivations: The role of affective and cognitive gratifications. Paper presented at the annual convention of the International Communication Association, Montreal, Canada.

Perse, E. M., \& Rubin, A. M. (1990). Chronic loneliness and television use. Journal of Broadcasting \& Electronic Media, 34, 37-53.

Raney, A. A. (2003). Disposition-based theories of enjoyment. In J. Bryant, D. RoskosEwoldsen, \& J. Cantor (Eds.), Communication and emotion: Essays in honor of Dolf Zillmann (pp. 61-84). Mahwah, NJ: Lawrence Erlbaum Associates.

Raney, A. A., \& Bryant, J. (2002). Moral judgment and crime drama: An integrated theory of enjoyment. Journal of Communication, 52, 402-415.

Rubin, A. M. (2008). Uses-and-gratifications perspective on media effects. In J. Bryant \& M. B. Oliver (Eds.), Media effects: Advances in theory and research (3rd ed., pp. 165-184). New York: Routledge.

Rubin, A. M. (1983). Television uses and gratifications: The interactions of viewing patterns and motivations. Journal of Broadcasting, 27, 37-51.

Ruggiero, T. E. (2000). Uses and gratifications theory in the 21 st century. Mass Communication \& Society, 3, 3-37.

Ryan, R. M., \& Deci, E. L. (2000). Self-determination theory and the facilitation of intrinsic motivation, social development, and well-being. American Psychologist, 55, 68-78. 
Schaefer, A., Nils, F., Sanchez, X., \& Philippot, P. (2005). A multi-criteria assessment of emotional films.Unpublished manuscript.

Scherer, K. R. (2001). Appraisal considered as a process of multilevel sequential checking. In K. R. Scherer, A. Schorr, \& T. Johnstone (Eds.), Appraisal processes in emotion (pp. 92120). New York: Oxford University Press.

Sparks, G. G. (1986). Developing a scale to assess cognitive responses to frightening films. Journal of Broadcasting \& Electronic Media, 30, 65-73.

Sparks, G. G. (1991). The relationship between distress and delight in males' and females' reactions to frightening films. Communication Research, 17, 625-637.

Strizhakova, Y., \& Krcmar, M. (2007). Mood management and video rental choices. Media Psychology, 10, 91-112.

Tamborini, R., \& Stiff, J. (1987). Predictors of horror film attendance and appeal: An analysis of the audience for frightening films. Communication Research, 14, 415-436.

Tan, E. S. (1996). Emotion and the structure of narrative film: Film as an emotion machine. Mahwah, NJ: Lawrence Erlbaum Associates.

Tesser, A., Millar, K., \& Wu, C. H. (1988). On the perceived functions of movies. Journal of Psychology, 122, 441-449.

Trepte, S. (2008). Cultural proximity in TV entertainment: An eight-country study on the relationship of nationality and the evaluation of US prime-time fiction. Communications, $33,1-25$.

Vorderer, P., Klimmt, C., \& Ritterfeld, U. (2004). Enjoyment: At the heart of media entertainment. Communication Theory, 14, 388-408. 
Vorderer, P., \& Ritterfeld, U. (in press). Digital games. In R. Nabi \& M. B. Oliver (Eds). Sage handbook of media processes and effects. Thousand Oaks, CA: Sage.

Vorderer, P., Steen, F., \& Chan, E. (2006). Motivation. In J. Bryant \& P. Vorderer (Eds.), Psychology of entertainment (pp. 3-17). Mahwah, NJ: Lawrence Erlbaum Associates.

Waterman, A. S. (1993). Two conceptions of happiness: Contrasts of personal expressiveness (eudaimonia) and hedonic enjoyment. Journal of Personality and Social Psychology, 64, $678-691$.

Weber, R., Tamborini, R., Lee, H. E., \& Stipp, H. (2008, May). Enjoyment of daytime soap operas: A longitudinal test of affective disposition theory. Paper presented at the annual meeting of the International Communication Association, Montreal, Canada.

Zillmann, D. (1988). Mood management through communication choices. American Behavioral Scientist, 31, 327-340.

Zillmann, D. (1998). Does tragic drama have redeeming value? Siegener Periodikum für Internationale Literaturwissenschaft, 16, 1-11.

Zillmann, D. (2000). Mood management in the context of selective exposure theory. In M. E. Roloff (Ed.), Communication Yearbook (Vol. 23, pp. 103-123). Thousand Oaks, CA: Sage.

Zillmann, D., \& Bryant, J. (1986). Exploring the entertainment experience. In J. Bryant \& D. Zillmann (Eds.), Perspectives on media effects (pp. 303-324). Hillsdale, NJ: Lawrence Erlbaum Associates.

Zillmann, D., \& Cantor, J. R. (1977). Affective responses to the emotions of a protagonist. Journal of Experimental Social Psychology, 13, 155-165. 
Zillmann, D., Hezel, R. T., \& Medoff, N. J. (1980). The effect of affective states on selective exposure to televised entertainment fare. Journal of Applied Social Psychology, 10, 323339.

Zuckerman, M. (1994). Behavioral expressions and biosocial bases of sensation seeking. Cambridge: Cambridge University Press.

Zuckerman, M. (1996). Sensation seeking and the taste for vicarious horror. In J. B. Weaver \& R. Tamborini (Eds.), Horror films: Current research on audience preferences and reactions (pp. 147-160). Mahwah, NJ: Lawrence Erlbaum Associates. 


\section{Authors' Note}

We extend our thanks to Matt Jordan and Matt McAllister for their assistance with data collection. We also thank Ron Tamborini for his helpful discussions with us about the issues addressed in this paper. 


\section{Footnotes}

${ }^{1}$ To explore whether artistic value emerged as a distinct factor with the reduced set of items selected for scale construction, we initially conducted a principal axis (PA) factor analysis using Promax rotation $(\kappa=4)$ with all 15 items included in the analysis. The eigenvalues and scree plot suggested that only four factors be extracted. Although items reflecting artistic value and meaning/though-provoking experiences loaded on the same factor, two of the artistic-value items had low loadings. As a result, we ran the analysis again extracting five factors to see if the artistic-value items would load on their own factor. This analysis was also unsatisfactory because although the artistic-value items loaded together on the fifth factor, several of the loadings were quite small, and one of the items cross-loaded. 
Table 1

Pattern Loadings, Reliabilities, and Descriptive Statistics for Developed Scales

\begin{tabular}{|c|c|c|c|c|c|}
\hline Audience Response Items & Fun & $\begin{array}{l}\text { Moving/ } \\
\text { Thought- } \\
\text { Provoking }\end{array}$ & $\begin{array}{l}\text { Lasting } \\
\text { Impression }\end{array}$ & Suspense & $\begin{array}{l}\text { Artistic } \\
\text { Value }\end{array}$ \\
\hline 1. It was fun for me to watch & & & & & \\
\hline this movie. & .89 & .01 & -.08 & -.05 & \\
\hline 2. I had a good time & & & & & \\
\hline $\begin{array}{l}\text { watching this movie. } \\
\text { 3. The movie was }\end{array}$ & .87 & .05 & .02 & .02 & \\
\hline entertaining. & .79 & -.05 & .04 & .01 & \\
\hline $\begin{array}{l}\text { 4. I found this movie to be } \\
\text { very meaningful. }\end{array}$ & -.01 & .87 & .02 & .02 & \\
\hline $\begin{array}{l}\text { 5. I was moved by this } \\
\text { movie. }\end{array}$ & .02 & .77 & .08 & -.02 & \\
\hline $\begin{array}{l}\text { 6. The movie was thought } \\
\text { provoking. }\end{array}$ & .01 & .72 & -.05 & .04 & \\
\hline $\begin{array}{l}\text { 7. This movie will stick with } \\
\text { me for a long time. }\end{array}$ & -.01 & -.04 & .99 & -.04 & \\
\hline $\begin{array}{l}\text { 8. I know I will never forget } \\
\text { this movie. }\end{array}$ & -.03 & -.01 & .85 & .01 & \\
\hline $\begin{array}{l}\text { 9. The movie left me with a } \\
\text { lasting impression. }\end{array}$ & .03 & .23 & .60 & .00 & \\
\hline $\begin{array}{l}\text { 10. I was at the edge of my } \\
\text { seat while watching this } \\
\text { movie. }\end{array}$ & .09 & -.13 & .18 & .79 & \\
\hline 11. This was a heart-pounding & & & & & \\
\hline kind of movie. & -.04 & .09 & -.03 & .77 & \\
\hline $\begin{array}{l}\text { 12. The movie was } \\
\text { suspenseful. }\end{array}$ & -.06 & .08 & -.14 & .73 & \\
\hline Eigenvalues & 4.69 & 2.51 & 1.30 & 0.93 & \\
\hline$\%$ Variance Explained & 39.06 & 20.94 & 10.84 & 7.77 & \\
\hline \multicolumn{6}{|l|}{ Artistic Value Items } \\
\hline $\begin{array}{l}\text { 1. I found the movie } \\
\text { artistically valuable. } \\
\text { 2. I found this movie } \\
\text { aesthetically strong. } \\
\text { 3. This movie is a cinematic } \\
\text { masterpiece. }\end{array}$ & & & & & \\
\hline Cronbach's $\alpha$ & 0.89 & 0.85 & 0.88 & 0.80 & 0.78 \\
\hline M & 6.20 & 3.85 & 4.81 & 3.95 & 4.10 \\
\hline$S D$ & 1.09 & 1.58 & 1.58 & 1.62 & 1.44 \\
\hline
\end{tabular}


Table 2

Study 1: Audience Responses as Predictors of Evaluation, Arousal, Valence, and Lasting Impression

\begin{tabular}{|c|c|c|c|c|c|}
\hline Audience Response & $\begin{array}{l}\text { Favorable } \\
\text { Evaluation }\end{array}$ & $\begin{array}{l}\text { Appreciation } \\
\text { - Enjoyment } \\
\end{array}$ & $\begin{array}{c}\text { SAM } \\
\text { Arousal }\end{array}$ & $\begin{array}{c}\text { SAM } \\
\text { Valence }\end{array}$ & $\begin{array}{c}\text { Lasting } \\
\text { Impression } \\
\end{array}$ \\
\hline Fun & $.72^{* * *}$ & $-.24^{* * *}$ & $.18^{* *}$ & $.61^{* * *}$ & $.32^{* * *}$ \\
\hline Suspense & .07 & .01 & $.39^{* * *}$ & $-.15^{* *}$ & $.18^{* *}$ \\
\hline $\begin{array}{l}\text { Moving/Thought- } \\
\text { Provoking }\end{array}$ & $.26^{* * *}$ & $.19^{* *}$ & .04 & $-.12^{*}$ & $.44^{* * * *}$ \\
\hline $\mathrm{R}^{2}$ & .64 & .09 & .21 & .40 & .43 \\
\hline$F$ & $154.53^{* * *}$ & $8.28^{* * * *}$ & $19.82^{* * *}$ & $55.77^{* * * *}$ & $64.79^{* * * *}$ \\
\hline
\end{tabular}

Note: Scores are standardized regression weights. 
Table 3

Study 1: Audience Responses by Genre

\begin{tabular}{lccc}
\hline \multirow{2}{*}{ Audience Response } & Comedy & Action/Thriller & Drama \\
\cline { 2 - 4 } Fun & $6.48_{\mathrm{a}}(.09)$ & $6.09_{\mathrm{b}}(.14)$ & $5.96_{\mathrm{b}}(.16)$ \\
Suspense & $2.89_{\mathrm{c}}(.11)$ & $5.19_{\mathrm{a}}(.17)$ & $4.21_{\mathrm{b}}(.19)$ \\
Moving/Thought-Provoking & $3.10_{\mathrm{c}}(.12)$ & $3.89_{\mathrm{b}}(.18)$ & $5.34_{\mathrm{a}}(.21)$ \\
\hline
\end{tabular}

Note: Numbers in parentheses are standard errors. Within rows, means with no subscripts in common differ at $p<.05$ using sequential Bonferroni procedures. 
Table 4

Study 2: Appreciation and Enjoyment Ratings by Film Type

\begin{tabular}{lcccc}
\hline & \multicolumn{4}{c}{ Film Condition } \\
\cline { 2 - 4 } $\begin{array}{l}\text { Audience } \\
\text { Response }\end{array}$ & Serious & Light & Action & Control \\
\hline Appreciation & $6.53_{\mathrm{a}}(.19)$ & $4.64_{\mathrm{c}}(.16)$ & $4.70_{\mathrm{c}}(.18)$ & $5.03_{\mathrm{b}}(.17)$ \\
Enjoyment & $5.80_{\mathrm{b}}(.14)$ & $6.45_{\mathrm{a}}(.11)$ & $5.87_{\mathrm{b}}(.13)$ & $6.20_{\mathrm{ab}}(.12)$ \\
\hline
\end{tabular}

Note: Numbers in parentheses are standard errors. Within rows, means with no subscripts in common differ at $p<.05$ using sequential Bonferroni procedures. 
Table 5

Study 2: Audience Responses by Film Type

Film Condition

\begin{tabular}{lcccc}
\cline { 2 - 5 } Audience Response & Serious & Light & Action & Control \\
\hline Fun & $5.62_{\mathrm{b}}(.15)$ & $6.35_{\mathrm{a}}(.12)$ & $5.71_{\mathrm{b}}(.14)$ & $5.97_{\mathrm{ab}}(.13)$ \\
Suspense & $4.81_{\mathrm{a}}(.19)$ & $2.81_{\mathrm{d}}(.16)$ & $5.14_{\mathrm{a}}(.18)$ & $3.97_{\mathrm{c}}(.17)$ \\
Moving/Thought-Provoking & $6.19_{\mathrm{a}}(.18)$ & $3.22_{\mathrm{c}}(.15)$ & $3.35_{\mathrm{c}}(.17)$ & $4.05_{\mathrm{b}}(.16)$ \\
\hline
\end{tabular}

Note: Numbers in parentheses are standard errors. Within rows, means with no subscripts in common differ at $p<.05$ using sequential Bonferroni procedures. 
Appreciation as Audience Response 51

Table 6

Study 2: Audience Responses as Predictors of Evaluation, Arousal, Valence, and Lasting Impression

\begin{tabular}{|c|c|c|c|c|c|}
\hline & Appreciation & Enjoyment & $\begin{array}{c}\text { SAM } \\
\text { Arousal } \\
\end{array}$ & $\begin{array}{c}\text { SAM } \\
\text { Valence }\end{array}$ & $\begin{array}{c}\text { Lasting } \\
\text { Impression }\end{array}$ \\
\hline \multicolumn{6}{|l|}{ Step 1} \\
\hline Serious Films & $.38^{* * *}$ & $-.16^{*}$ & -.01 & $-.29^{* * *}$ & $.43^{* * *}$ \\
\hline Light Films & -.11 & .11 & .00 & $.40^{* * *}$ & .11 \\
\hline Action Films & -.09 & -.13 & .08 & .03 & .06 \\
\hline $\mathrm{R}^{2}$ & .21 & .06 & .01 & .32 & .15 \\
\hline$F$ & $22.36^{* * *}$ & $5.93^{* * *}$ & 0.50 & $36.03^{* * *}$ & $15.20^{* * *}$ \\
\hline \multicolumn{6}{|l|}{ Step 2} \\
\hline Fun & $.12^{*}$ & $.65^{* * *}$ & .01 & $.42^{* * *}$ & $.27^{* * *}$ \\
\hline Suspense & .04 & .03 & $.34^{* * *}$ & $-.15^{*}$ & $.26^{* * *}$ \\
\hline $\begin{array}{l}\text { Moving/Thought- } \\
\text { Provoking }\end{array}$ & $.58^{* * *}$ & .03 & .10 & .09 & $.44^{* * *}$ \\
\hline $\mathrm{R}^{2}$ Change & .24 & .41 & .11 & .16 & .43 \\
\hline$F$ Change & $36.62^{* * *}$ & $67.78^{* * *}$ & $9.09^{* * *}$ & $23.11^{* * *}$ & $64.79^{* * *}$ \\
\hline
\end{tabular}

Note: Scores are standardized regression weights. 
Table 7

Study 3: Audience Response Dimensions by Film

\begin{tabular}{|c|c|c|c|c|c|c|c|}
\hline \multirow[b]{2}{*}{ Film } & \multicolumn{4}{|c|}{ Audience-Response Dimensions } & \multicolumn{3}{|c|}{ Fit Statistics } \\
\hline & Fun & Suspense & $\begin{array}{l}\text { Moving/ } \\
\text { Thought- } \\
\text { Provoking }\end{array}$ & $\begin{array}{c}\text { Lasting } \\
\text { Impression }\end{array}$ & $\chi^{2} / \mathrm{df}$ & CFI & RMSEA \\
\hline \multicolumn{8}{|c|}{ The Graduate $(N=214)$} \\
\hline Cronbach's $\alpha$ & .89 & .83 & .85 & .85 & 1.54 & .98 & .05 \\
\hline$M$ & 6.10 & 3.71 & 4.47 & 5.20 & & & \\
\hline$S D$ & 0.93 & 1.43 & 1.34 & 1.27 & & & \\
\hline \multicolumn{8}{|c|}{ Bladerunner $(N=223)$} \\
\hline Cronbach's $\alpha$ & .93 & .89 & .90 & .94 & 2.52 & .97 & .08 \\
\hline$M$ & 3.57 & 3.61 & 3.31 & 3.28 & & & \\
\hline$S D$ & 1.65 & 1.51 & 1.58 & 1.62 & & & \\
\hline \multicolumn{8}{|c|}{ Dr. Strangelove $(N=276)$} \\
\hline Cronbach's $\alpha$ & .88 & .77 & .75 & .87 & 3.41 & .94 & .09 \\
\hline$M$ & 4.75 & 3.07 & 3.94 & 3.93 & & & \\
\hline$S D$ & 1.45 & 1.34 & 1.37 & 1.51 & & & \\
\hline
\end{tabular}


Table 8

Study 3: Audience Responses as Predictors of Evaluation and Lasting Impression

\begin{tabular}{|c|c|c|c|c|c|c|c|c|c|}
\hline & \multicolumn{3}{|c|}{ Good Movie } & \multicolumn{3}{|c|}{ Appreciation - Enjoyment } & \multicolumn{3}{|c|}{ Lasting Impression } \\
\hline & $\mathrm{G}$ & $\mathrm{B}$ & $\mathrm{D}$ & & $\mathrm{B}$ & $\mathrm{D}$ & $\mathrm{G}$ & $\mathrm{B}$ & $\mathrm{D}$ \\
\hline \multicolumn{10}{|l|}{ Audience Response } \\
\hline Fun & $.74^{* * *}$ & $.64^{* * *}$ & $.71^{* * *}$ & -.09 & $-.40^{* * * *}$ & $-.19^{*}$ & $.44^{* * *}$ & $.25^{* * *}$ & $.45^{* * *}$ \\
\hline Suspense & .05 & .08 & .01 & .03 & -.02 & .07 & .07 & $.19^{* * *}$ & .07 \\
\hline $\begin{array}{l}\text { Moving/Thought- } \\
\text { Provoking }\end{array}$ & .03 & $.23^{* * *}$ & $.20^{* * *}$ & .12 & $.44^{* * * *}$ & $.18^{+}$ & $.42^{* * *}$ & $.49^{* * *}$ & $.37^{* * *}$ \\
\hline $\mathrm{R}^{2}$ & .62 & .80 & .72 & .01 & .08 & .04 & .63 & .74 & .61 \\
\hline$F$ & \multicolumn{3}{|c|}{$107.61^{* * *} 280.54^{* * *} 209.67^{* * *}$} & 0.91 & $5.80^{* * *}$ & 2.56 & \multicolumn{3}{|c|}{$117.34^{* * *} 210.53^{* * *} 139.70^{* * *}$} \\
\hline
\end{tabular}

Note: Scores are standardized regression weights. $\mathrm{G}=$ Graduate $; \mathrm{B}=$ Bladerunner $; \mathrm{D}=$ Dr. Strangelove 